\title{
Decreasing the residential energy consumption in the Portuguese residential sector: potential of energy saving behaviours
}

\author{
C. Sabino \& A. G. Martins \\ Energy for Sustainability Initiative, University of Coimbra, Portugal
}

\begin{abstract}
Buildings are part of a city, being the residential buildings responsible for a considerable share of the energy consumption. The energy consumption associated with the different residential energy services (lighting, cooking, water heating, etc.) is influenced by the way consumers use each of them. Accordingly, consumers play an important role on the residential energy consumption and up to $20 \%$ energy savings can be achieved by actions targeting behaviour. This work focuses on the Portuguese case, and analyses the adoption rate of a set of energy saving behaviours associated with a group of residential equipment: lighting systems, washing machine, refrigerator, television, computer and dishwasher. The most common consumers' behaviour were identified $\mathrm{f}$ or e ach e quipment, and Portuguese studies which quantitatively evaluated the adoption rates of those behaviours were reviewed. A comparison is performed concerning the different values of adoption rates obtained from different studies. The different scopes and methodologies employed by the different studies make the comparison a challenging task. Behaviours, which the adoption rate did not address in previous studies conducted in the country, are identified, such as the case of using daylight, instead of artificial light, during the day.
\end{abstract}

Keywords: residential buildings, energy savings, energy consumption, behaviour, equipment, adoption rate.

\section{Introduction}

It is consensual that solutions leading to sustainability are essential. Being the cities responsible for the largest consumption of energy resources and the buildings 
one of the most important physical elements of a city, it is important to design and implement measures which lead to sustainable development at the urban level.

With a considerable share of the population moving to cities in last decades, the residential buildings are responsible for a considerable share of the energy consumption of a city. The energy required for cooking, air heating, water heating, air cooling, lighting and other electric equipment are the main residential final energy uses demand, mostly fulfilled by electricity. Another essential element of a city is the population who works and lives there, influencing the energy consumption of the buildings, and consequently of the city. In this way, the users of the buildings play a crucial role on the residential energy consumption of a city.

During the last decades, general energy efficiency policies in OECD countries have focused essentially on increasing the energy efficiency of buildings, appliances, vehicles and industrial equipment and operations, and less attention has been paid to changing the way consumers use energy (Geller et al. [13]). Indeed, it has been asserted that measures targeting behaviour change can lead to potential energy savings up to $20 \%$ [1]. Behaviour change may affect two types of behaviours: i) investment behaviours, which are related to the adoption of new technology (new equipment) and occur occasionally, and ii) habitual behaviours, which are considered a routine, and are automatically repeated by consumers without a previous evaluation of its consequences.

The Portuguese population already adopt some energy saving behaviours. However, its adoption rate may have potential to be enhanced. The aim of this work is to summarize quantitative values of the adoption rates of some energy saving behaviours likely to be adopted in the residential sector, i.e. the share of Portuguese population who claims to adopt specific energy saving behaviours. Wherever possible, based on values gathered from different studies, it is aimed to present confidence intervals of the adoption rate of some of them.

\section{Methodology}

Under the scope of this work, a set of equipment was selected to be analysed according to four decision criteria: the ownership rate of the equipment, its annual energy consumption, its load diagram shape and a measure of the availability of general quantitative data. From a list of 25 different types of residential equipment it was concluded that the lighting systems, the washing machine, the refrigerator, the microwave oven, the television, the computer and the dishwasher are the most relevant equipment to be analysed. However, despite its relevance, the microwave oven had to be cut off from the analysis due to lack of relevant quantitative information.

For the referred set of equipment, the most common types of energy saving behaviours were identified. With the aim of connecting demand-side management actions with behaviour change programs, the identified behaviours were grouped by the type of loads they represent. Accordingly, four groups of loads were defined: investment dependent loads (investing in a more efficient equipment), loads prone to energy conservation actions (using the equipment in a more conservative way), 
Table 1: Behaviours associated with loads prone to energy conservation actions.

\begin{tabular}{|c|c|}
\hline Equipment & Behaviour \\
\hline \multirow{2}{*}{$\begin{array}{l}\text { Lighting } \\
\text { systems }\end{array}$} & Using daylight \\
\hline & Turning off \\
\hline \multirow{5}{*}{$\begin{array}{l}\text { Washing } \\
\text { machine }\end{array}$} & Using low washing temperatures \\
\hline & Using full capacity \\
\hline & Avoiding opening the door \\
\hline & Maintaining the door seals in proper conditions \\
\hline & Avoiding keeping warm food inside \\
\hline \multirow[t]{4}{*}{ Refrigerator } & Unfreezing food inside \\
\hline & Removing the layer of ice \\
\hline & $\begin{array}{l}\text { Keeping the auxiliary ventilator and condenser in good } \\
\text { operating condition }\end{array}$ \\
\hline & Re-thinking the location \\
\hline \multirow{4}{*}{$\begin{array}{l}\text { Television and } \\
\text { Computer }\end{array}$} & Interrupting the operation (either by switching it off or \\
\hline & leaving it in stand-by) \\
\hline & Switching off the supply (avoiding the stand-by mode) \\
\hline & Using low washing temperatures \\
\hline \multirow[t]{2}{*}{ Dishwasher } & Allowing natural drying \\
\hline & Using full capacity \\
\hline
\end{tabular}

deferrable loads (using the equipment in a different period of the day, indirectly contributing to energy savings.) and loads responding to changeable parameter settings (adjusting the thermostatic parameters of the equipment in order to save energy). Table 1 identifies, for the six selected equipment, the types of behaviours associated with loads prone to energy conservation actions, the only type of load addressed in this work.

Apart from the loads prone to energy conservation actions being the only type of load considered, behaviours associated with the other types of loads include: replacing the equipment by a more efficient one (investment depend load associated with the lighting systems, washing machine, refrigerator and dishwasher), applying sensors/regulators in lighting systems (investment dependent load), shifting the usage period of the washing machine and dishwasher (deferrable load) and regulating the operating temperature of the refrigerator (load responding to changeable parameter settings).

Taking into account the Portuguese population and the selected equipment and behaviours, several Portuguese studies which addressed energy saving behaviours 
in a quantitative way were reviewed. Only studies which reported surveys in one of the phases were considered.

Mainly two different types of works were reviewed: 1) studies and reports carried out by national entities, whose data reflect the reality of the country, at a certain reference year and 2) studies based on surveys launched among a certain sample, in a voluntary basis or not, which may be or may not be representative of the country. Moreover, all the studies had different scopes and methodologies.

Wherever possible data from different studies are combined and average values of the adoption rates of behaviours are computed, by weighting the sample size of each study.

Different questionnaires were used in the surveys conducted by the studies reviewed, making sometimes difficult to combine the results from the studies to obtain average values. Particularly, some studies addressed the adoption frequency of a certain behaviour (e.g. always, sometimes, never) and others did not. Moreover, among the studies which considered the adoption frequency different scales and qualitative values were used. For this reason, in order to combine the data from different studies, the cumulative sum of the values corresponding to adoption frequencies from always to sometimes, was considered, instead of the individual values of each frequency. As a result, by doing so, some information is lost. Additionally, for studies not addressing the adoption frequency, the qualitative value was considered that corresponds to the middle point of a generic Likert scale of frequency ranging from never to always, i.e. sometimes.

\section{Adoption rates of energy saving behaviours}

This section presents a review of the adoption rate of the behaviours, stated in Table 1, referent to loads prone to energy conservation actions.

\subsection{Lighting systems}

The saving behaviours most commonly referred associated with lighting systems are related to turning the lights off when not necessary and using daylight instead of artificial light during the day. However, no data could be collected concerning behaviours associated with daylight use.

\subsubsection{Turning the lights off}

Several studies reported conclusions about the habit of turning the lights off when not necessary. One of these studies concluded that $62 \%$ of the sample almost always adopt the referred behaviour [2]. Another study seem to be in agreement with this value [3]. According to Rebelo et al. [3], 57\% of the respondents claim to almost always turn the lights off when leaving a room and it becomes empty, and $61 \%$ claim to almost never leave the lights on when nobody is in the room, the complementary of the former [3].

Another study, analysed, for five Portuguese regions covering the country, the adoption rate of turning the lights off when not necessary, but not referring any 


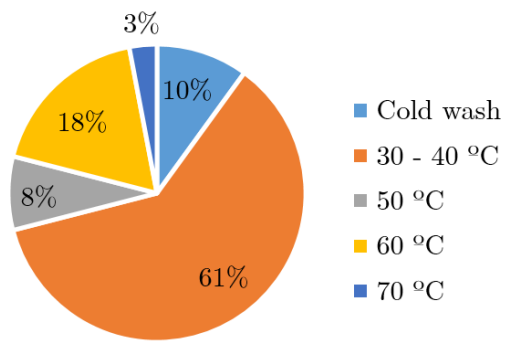

Figure 1: Habitual washing temperatures used in washing machines [6].

adoption frequency [4]. Values presented in this study are slightly higher than the ones previously referred, varying from 75 to $85 \%$. For the country, the average adoption rate is $81 \%$ [4].

An additional study, considered a Likert scale of seven points (from never to always), and concluded that on average the respondents claimed to often turn the lights off when leaving a room for more than 5 minutes or before leaving it. $57 \%$ of the sample referred to, at least sometimes, turn the lights off when leaving a room for more than 5 minutes or before leaving it. Similarly, considering a scale from very improbable to very probable, the same study concluded that, on average, the respondents claim it to be probable to try in the next 2 months to turn the lights off when leaving a room for more than 5 minutes or before leaving it [5].

Considering the studies referred above, on average, from a total of 4332 equivalent individuals, $62 \%$ of them claim to turn the lights off when leaving a room, representing $0.04 \%$ of the total population of Portugal. It can be said that the adoption rate of this behaviour varies between 44 and $81 \%$, with a confidence level of $95 \%$.

\subsection{Washing machine}

Associated with the washing machine, the use of low temperature cycles and the use of its total capacity are the most common behaviours.

\subsubsection{Using low washing temperature}

Some studies evaluated the behaviour associated with the temperature used in the washing machine's cycles. However, it is notable that the results particularly depend on the sample. For one of the samples, Figure 1 shows the number of households usually using a certain washing temperature [6]. According to Figure $1,71 \%$ of the households habitually use low temperature washing cycles (temperatures up to $40^{\circ} \mathrm{C}$ ), whereas almost $20 \%$ of them use 60 -degrees washing cycles.

Another study concluded that only $12 \%$ of the respondents use low temperature washing cycles [2], strongly contrasting with the values obtained within the 


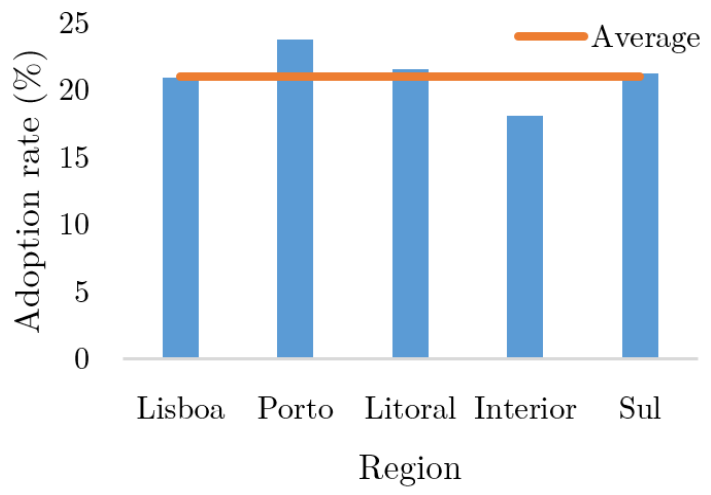

Figure 2: Adoption rate, by region, of using washing machine only when full (ADENE [4]).

EcoFamílias project, which conclude that among all the households, $87 \%$ use washing cycles limited to $40^{\circ} \mathrm{C}$ [7].

Considering the wide range of values referred by the cited studies, it is not possible to combine the values to estimate an average value with an acceptable confidence level.

\subsubsection{Using its full capacity}

Several studies addressed the habit of using the washing machine only when its total capacity is fulfilled. Figure 2 presents the results obtained in one of these studies [4]. The study evaluated this type of behaviour for different Portuguese regions. In this case, the variation between the regions is not significant and the average of the adoption rate for all the regions is as low as $21 \%$. Even lower, was the adoption rate of $9 \%$ obtained by Energaia [2], which also evaluated this type of behaviour for different regions. On the contrary, Pinheiro [8] concluded that $80 \%$ of the respondents use the washing machine at its full capacity. However, this study is referent to a building complex in Lisbon, a strict sample, in opposition to the other two studies referred.

Two other studies, besides evaluating the adoption rate of this behaviour, also considered its adoption frequency. This fact, hamper the comparison with the previous studies. The adoption rates obtained in both are relatively in agreement. One of them pointed that $79 \%$ of the respondents declared to always use the washing machine when full, $19 \%$ of them sometimes and only $2 \%$ of them claimed to almost never use it when full [9]. According to another study [10], around 85\% of the respondents declared to always use the washing machine when full.

Since for this type of behaviour a wide range of values were collected, it is not possible to combine the values to obtain an estimation of an average value for the adoption rate with an acceptable confidence level. 


\subsection{Refrigerator}

The refrigerator is the equipment to which the largest number of different behaviours was collected. The most common behaviours associated with the refrigerator are related to the number of times and period of door's openings, the non-existence of a layer of ice in the internal surfaces of the freezer compartment, its correct location and habits of unfreezing and do not keeping warm food inside it. Moreover, behaviours related to its maintenance, as keeping the seals, the condenser and the auxiliary ventilator in good operating conditions are also included.

Regarding the habit of opening the refrigerator's door, Rebelo et al. [3] concluded that more than half of the sample almost always close the refrigerator's door quickly when using it, avoiding keeping it open for long periods. However, this was the only study addressing this type of behaviour.

Concerning the existence of a layer of ice superior to 5 millimetres on the surfaces of the freezer compartment, no information could be collected.

Despite the large number of potential energy saving behaviours, compared to the other energy services analysed, little information about behaviours associated with refrigerators could be gathered. No studies were found concerning the habit of do not keeping warm food inside the refrigerator or unfreezing food inside it as well as the behaviours associated with its maintenance (keeping the seals, the condenser and the auxiliary ventilator in good operating conditions).

\subsection{Television and computer}

Associated with the television and computer there are two distinct behaviours which may be confused to one another. One of them consists of interrupting the equipment operation when not necessary (either by turning it off completely or leaving it in stand-by mode), and the other consists of actually switching off the supply, avoiding the stand-by mode.

\subsubsection{Switching off the supply}

Considering the electric equipment in general, and not specifically the television and the computer, several studies presented values about the habit of switching off the supply of the equipment instead of leaving them in stand-by mode. From the studies reviewed, the adoption rate of this type of behaviour varies between 35 and $61 \%$. However, in three of them, this range is shortened to values between 40 and $49 \%[2,4,10]$.

According to Energaia [2], 44\% of the respondents claim to switch off the equipment's supply, not leaving them in stand-by mode. Quite similar values are presented in another study [10], which also compared the differences between households inside and outside Lisbon. A third study, which analysed different Portuguese regions, concluded that on average the adoption rate of this behaviour is $49 \%$ [4]. Two other studies [3,9] evaluated the habit of leaving the equipment in stand-by mode instead of switching off its supply, i.e. the complementary 


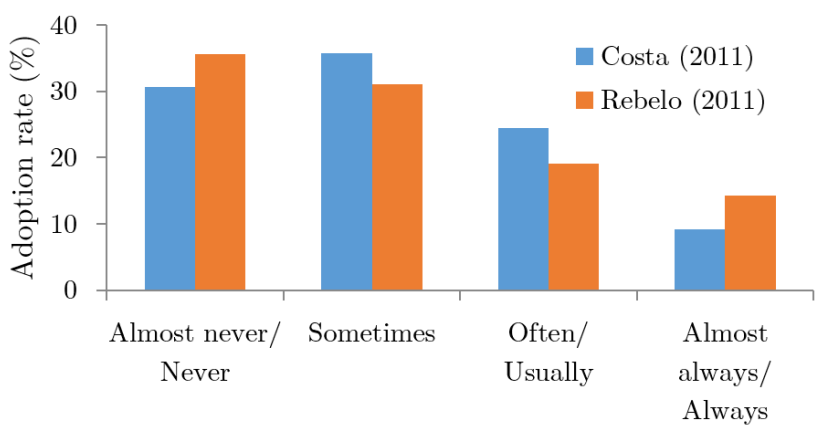

Frequency of adoption

Figure 3: Adoption rate and frequency of leaving the equipment in stand-by mode (instead of switching it off) [3,9].

behaviour of switching off the supply. Both studies present values in agreement with each other, as shown in Figure 3.

Assuming that "never leaving the equipment in stand-by mode" is equivalent to "always switching off the equipment's supply", according to Figure 3 it is possible to conclude that $66 \%$ of the respondents usually switch the equipment off (i.e., almost never, never or sometimes leave the equipment in stand-by mode).

The average of the adoption rate presented in the referred studies, corresponding to 12,077 equivalent individuals $(0.12 \%$ of the total Portuguese population), is $40 \%$, varying between 23 and $57 \%$, with a confidence level of $95 \%$.

Regarding the television individually, it is known that from the 7,475,656 televisions existing in the Portuguese households in 2011 (on an average of two televisions per household), $43 \%$ were usually left in stand-by mode, as national statistics at country level show [11]. Considering this number, it may be assumed that $57 \%$ were usually switched off. However, when studies are targeted to small samples, different values may be obtained. For example, Morais [12] concluded for a neighbourhood that only $30 \%$ of the respondents switch off the television's supply, half of the value claimed by national statistics.

In the case of the computer, according to national statistics, from the 3,102,548 computers existing in the Portuguese households in 2011 (on average one computer per household), only $10 \%$ were usually left in stand-by mode [11], meaning that $90 \%$ of them were usually switched off. In comparison to the neighbourhood study [12], similar values were achieved, also for the cases of monitor and laptop. According to this study, a big difference exists between the behaviours associated with the desktop and the laptop: $90 \%$ of the respondents claim to switch off their desktop, whereas only $50 \%$ claim to switch off their laptop. 


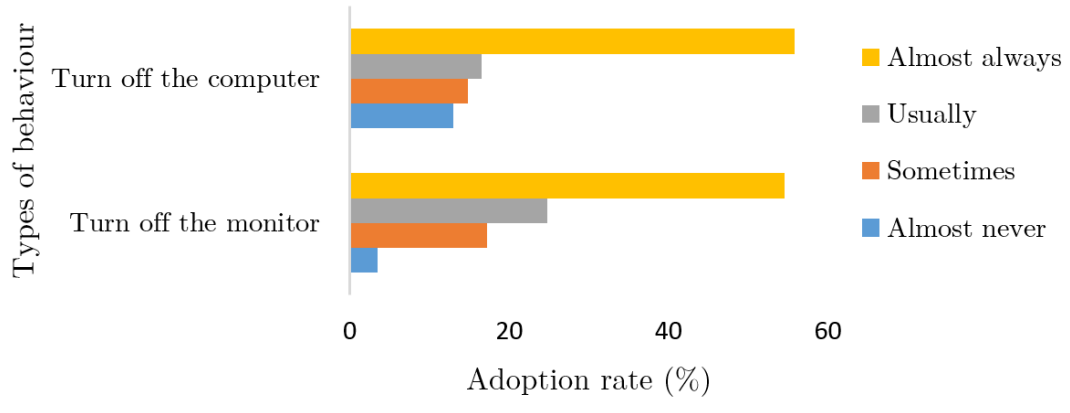

Figure 4: Adoption rate and frequency of interrupting the operation of the computer and its monitor [3].

\subsubsection{Interrupting the operation}

Concerning the behaviour associated with interrupting the television and/or the computer's operation when they are not being used, little information was gathered. However, regarding the residential equipment in general, Ferreira [10] concluded that on average $15 \%$ of the respondents often leave the equipment on when not using it, therefore allowing to assume that $85 \%$ often interrupt its operation when not using it.

Regarding the computer, according to Rebelo et al. [3], around 55\% of the sample claim to almost always interrupt the computer and its monitor's operation when not using them, as shown in Figure 4. In a general way, interrupting the computer's monitor operation when not in use appears to be a more adopted behaviour when compared to interrupting the computer's operation.

Summing up the adoption rates of the respondents claimed to almost always, usually or sometimes adopt these behaviours, it can be said that 87 and $97 \%$ often interrupt the operation of their computer and the computer's monitor, respectively [3]. Similar values were found in [12], concluding that $92 \%$ interrupts the operation of the computer's monitor when not using it and $97 \%$ the television operation, either by switching them off or leaving them in stand-by mode. Besides, [12] also refers rates of $100 \%$ for the case of the computer (desktop and laptop).

\subsection{Dishwasher}

The behaviours associated with the dishwasher are related to using low temperature washing cycles, fulfilling its total capacity and allowing the natural drying of the dishes by skipping the drying phase. No data could be gathered concerning the last one.

\subsubsection{Using low washing temperature}

There are some studies concerning the dishwasher's washing temperature. However, similarly to the case of the washing machine, the adoption rate of a 


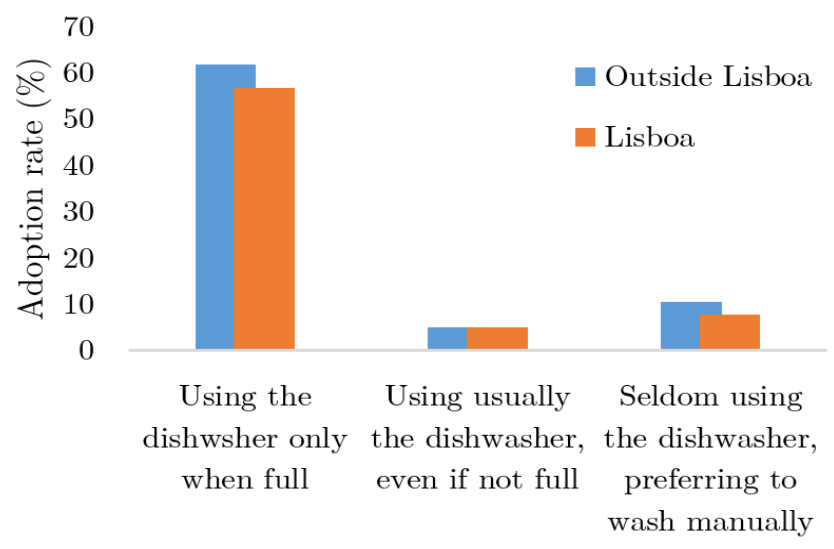

Type of behaviour

Figure 5: Adoption rate of behaviours associated to dishwasher's usage [10].

certain temperature considerably varies from study to study. Besides, the different questions used in the surveys used by different studies make it difficult to perform a comparison among the values obtained.

According to Carvalho [6], almost half of the respondents use temperatures between 50 and $65^{\circ} \mathrm{C}$. Temperatures between 30 and $45^{\circ} \mathrm{C}$ are used by $37 \%$ of the users. However, in other study it was concluded that only $12 \%$ of the sample use low temperature washing cycles, not specifying the temperature [2]. A last study, concluded that $56 \%$ of the sample used temperatures higher than $60^{\circ} \mathrm{C}$ [7], which may allow assuming that $44 \%$ use low washing temperatures.

Since the values referred for this type of behaviour vary significantly, it is not possible to estimate an average value of its adoption rate with an acceptable confidence level.

\subsubsection{Using its full capacity}

The use of the dishwasher only when full is an adopted behaviour by around $60 \%$ of the respondents of a questionnaire launched at the country level, as shown in Figure 5 [10]. According to Figure 5, the use of the dishwasher at its total capacity is a habit always adopted by around $60 \%$ of the respondents, assuming only $5 \%$ of them to usually use it even if not full. A slightly higher adoption rate was presented in another study [8], which concluded that $80 \%$ of the users use the dishwasher at its full capacity, not mentioning any adoption frequency. In contrast, only $9 \%$ of the sample considered in [2] claim to adopt such behaviour.

Since the values referred for the adoption rate of this type of behaviour also vary significantly, it is not possible to estimate an average value with an acceptable confidence level. 


\section{Conclusion}

From the set of behaviours identified, information from previous studies could be gathered about the following behaviours: i) lighting systems: turning off the lights; ii) washing machine: using low washing temperatures and using its full capacity; iii) refrigerator: avoiding opening the door often; iv) television and computer: interrupting the operation and switching off the supply, and v) dishwasher: using low washing temperatures and using its full capacity. However, only one study could be collected referring to behaviours associated with avoiding opening the refrigerator's door and interrupting the operation of the television and computer when not being used. No relevant data could be collected regarding some behaviours associated with three equipment: i) lighting systems: using of daylight; ii) refrigerator: removing the layer of ice from the internal surfaces of the freezer compartment, do not keeping warm food or unfreezing food inside it and the behaviours associated with its maintenance and its location and iii) dishwasher: allowing the natural drying of the dishes.

For the majority of the behaviours analysed, it was only possible to combine, with an acceptable confidence level, the behaviours associated with turning off the lights when not necessary, ranging the adoption rate from 44 to $81 \%$, and with switching off the supply of the television and the computer, ranging from 23 to $57 \%$.

As a general conclusion, it can be said that studies were reviewed with relevant information related to the majority of the identified behaviours. However, that information varies significantly from study to study. This fact may be mainly due to the methodology employed and the sample considered by each one, i.e. the size of the sample and its type (very strict samples, convenience samples, voluntary samples, etc.). Moreover, the use of different types of questions to obtain similar information, makes the comparison among the studies a challenging task.

\section{References}

[1] European Environment Agency, Achieving energy efficiency through behaviour change: what does it take?, 2013.

[2] Energaia, Transformar atitudes em ação: perfil energético do setor residencial (Projeto Energy Profiler), 2011.

[3] Rebelo, M., Menezes, M., Almeida, S., Schmidt, L., Horta, A., Fonseca, S. \& Correia, A., Net Zero Energy Schools: Resultados gerais de um inquérito em contexto escolar sobre atitudes, representações e práticas de uso de energia, 2011.

[4] ADENE, Mudança de Comportamento no âmbito da Eficiência Energética. Technical report, ADENE/DATA E, 2011.

[5] János, L., Students Energy Saving Behavior-Case study of University of Coimbra. Master Thesis, University of Coimbra, 2011.

[6] Carvalho, N., Avaliação do potencial de poupança de energia elétrica em residências através de monitorização inteligente. Master thesis, Universidade Nova de Lisboa, 2013. 
[7] Ferreira, F., Antunes, A.R., Alves, A.F., Ramos, S., Gomes, R., Verdasca, C., Campos, S., Dias, A.P.a., Santos, P.S., Pinto, I., Pereira, N., Carlos, F., Sousa, F.M.N. \& Fonseca, S., Projecto EcoFamílias - Relatório Final. Technical report, Quercus - Associação National de Conservação da Natureza, 2008.

[8] Pinheiro, L., Análise sócio-demográfica para a caracterização de consumos domésticos em sistemas de distribuição de água. Instituto Superior Técnico, Lisboa, 2008.

[9] Costa, G., Atitudes e Comportamentos das Famílias Sobre Consumo Sustentável. Master thesis, Universidade Aberta, 2011.

[10] Ferreira, A.G., Levantamento dos hábitos ambientais a nível doméstico dos agregados familiares lisboetas. Propostas de melhoria e elaboração de um guia de boas práticas ambientais. Master thesis, Universidade de Lisboa, 2009.

[11] INE, I., Inquérito ao Consumo de Energia no Sector Doméstico 2010. Technical report, Instituto Nacional de Estatística, IP, Lisbon, Portugal, 2011.

[12] Morais, L., Consumos Energéticos no Sector Residencial: um caso de estudo. Ph.D. thesis, Universidade de Trás-os-Montes e Alto Douro, 2009.

[13] Geller, H., Harrington, P., Rosenfeld, A.H., Tanishima, S., Unander, F. \& Dahlbom, B., Policies for increasing energy efficiency: Thirty years of experience in OECD countries. Energy Policy, 34, pp. 556-573, 2006. 